\title{
RadCases Plus Q\&A Pediatric Imaging: Richard B. Gunderman and Lisa R. Delaney (eds)
}

\author{
Published by Thieme Medical Publishers, New York, USA; Second Edition: \\ 2019; ISBN: 978-1-62623-519-9
}

\author{
Manisha Jana ${ }^{1}$
}

Received: 8 April 2019 / Accepted: 9 April 2019 / Published online: 24 April 2019

(C) Dr. K C Chaudhuri Foundation 2019

This book comes in the format of a collection of case vignettes. It consists of 100 cases, a brief description of all the cases, the essential imaging features and their differential diagnoses. At the end, there are multiple choice questions with their answers and explanations. It covers almost all the common pediatric disease entities.

While going through the pages, what attracts the readers most is the excellent quality of the images. Printed in good resolution and appropriate size, it is a pleasure to do the brainstorming with them! The discussions are crisp, and avoid redundant text. The questions and answers at the end are additional attractions. Also, the readers get a fair idea of related articles and books, useful for further reading. A fair mix of conventional images, $\mathrm{CT}$ and MRI makes the book complete. It is an absolute delight to read! And what more, it comes with an access to 350 cases for online self-test.

Manisha Jana

manishajana@gmail.com

1 Department of Radiology, All India Institute of Medical Sciences, Ansari Nagar, New Delhi 110029, India
However, while flipping through the pages, one may feel that addition of a few clinical entities such as chest radiographs of a few more common congenital heart diseases and common skeletal dysplasias, malignancies (such as neuroblastoma, retinoblastoma and hematologic malignancies) would make the book even more useful to the residents in training.

This book is useful for the pediatricians, pediatric radiologists and radiology residents; and a boon to all those preparing for their exams in radiology. Handy and informative, it is a good choice for the next book in your 'radiology bucket list'!

Publisher's Note Springer Nature remains neutral with regard to jurisdictional claims in published maps and institutional affiliations. 